\title{
Education within Sustainable Development: Critical Thinking Formation on ESL Class
}

\author{
Inna Pevneva ${ }^{1, *}$, Olga Gavrishina ${ }^{2}$, Anna Smirnova $^{3}$, Elena Rozhneva ${ }^{4}$, and \\ Nataliya Yakimova ${ }^{5}$ \\ ${ }^{1}$ Kemerovo institute (branch) of Plekhanov Russian University of Economics, Department of \\ Humanities, 65099239 Kuznetsky pr., Kemerovo, Russia \\ ${ }^{2}$ Kemerovo State University, Institute of Sciences, UNESCO IT department, 6500006 Krasnaya ul., \\ Kemerovo, Russia \\ ${ }^{3}$ Kemerovo State University, Department of Germanic and Romance studies, 6500006 Krasnaya ul., \\ Kemerovo, Russia \\ ${ }^{4}$ T.F. Gorbachev Kuzbass State Technical University, Department of foreign languages, 65000028 \\ Vessennyaya st., Kemerovo, Russia \\ ${ }^{5}$ Kemerovo State University, Department of Foreign Languages in Professional Communication, \\ 6500006 Krasnaya ul., 6, Kemerovo, Russia
}

\begin{abstract}
The article is devoted to consideration of the critical thinking formation in course of foreign language teaching within the education for sustainable development as a crucial skill of perspective employee and a future leader of Russian employment market. The necessity to include the component of problem education and critical thinking methodology in course of the foreign language class is justified along with analysis of the basic principles of critical thinking and certain strategies that can be implied in class. This model targets communicative language competences of students as well as critical thinking due to interconnection of various types of cognitive activities in class. The role in personality development of the students is considered along with the formation and enhancing of critical thinking skills within the modern personality-oriented approach.
\end{abstract}

\section{Introduction}

Education for sustainable development allows each person to acquire the knowledge and skills and to form the attitudes and values necessary to build a sustainable future. Education for sustainable development involves teaching and learning the main issues related to sustainable development such as climate change, biological diversity, poverty reduction and sustainable consumption. It also implies the use of methods based on participation, motivating students and allowing them to adapt and become active participants of sustainable development. In this regard, education within sustainable development would seek to develop critical thinking ability and qualities that allow graduates to predict certain crucial events in the future and take correct decisions [1-2]. Nowadays we obviously

\footnotetext{
* Corresponding author: Inna nag@mail.ru
} 
witness that sustainable development can not be achieved solely through technology, political regulation or financial mechanisms. Mankind needs to change the way of thinking and behavior, thus requiring to provide quality education and training for sustainable development at all levels and independently of social conditions.

Situation on Russian graduate market has its specifics, but in general is close to European and American. Employers increasingly recognize what they want to see in graduates is not so much technical knowledge, but applied skills, including critical thinking and abilities to take justified decisions. According to a report of employers' perspectives, a consortium of more than 400 US employers ranked "critical thinking" as the most desirable skill in new employees. It was ranked higher than skills in "innovation" and "application of information technology" [3].

\section{Methods}

One of the technologies that present enormous opportunities for solving this problem is the technology of developing critical thinking through reading and writing, developed in the 80 s of the 20th century in the USA. Even at the beginning of the twentieth century, D. Dewey spoke of critical thinking identifying it with reflective thinking. He believed that through exercises you can teach a person to think constructively and saw in this the main task of education. The task of education, in his opinion, is precisely to develop intelligence and form a "disciplined" mind [4-6].

Academics and researchers for the most part understand critical thinking as a cognitive strategy, consisting largely of continuous challenging and testing of possible solutions. Other definitions indicate that critical thinking is characterized by constructing logical conclusion as well as creating consistent logical models and taking justified decisions. They refer to the mental activity which is aimed at solving a particular cognitive task [7-8]. The mechanism of critical thinking includes mental operations that determine the process of reasoning and argumentation: setting the goal, identifying the problem, putting forward hypotheses, bringing arguments, justifying them, predicting the consequences, accepting or rejecting alternative options. It includes the ability to apply basic intellectual skills (knowledge and understanding) for the synthesis, analysis and evaluation of complex and ambiguous situations and problems.

There are basic principles that characterize the development of critical thinking. Each of these principles to a certain degree can be considered a mental skill so they should be given great attention in the process of students' education. First, a student can identify and challenge assumptions. It can be verified by posing special questions that clarify the details. Students should study the grounds on which the conclusion was drawn and analyze whether the various sides of this conclusion are facts or opinions. Secondly, it should come to verification of actual accuracy and logical sequence checking the logical coherence and consistency in the argument. The third principle is based on context consideration. Upon considering new information, a person having critical thinking skills will pay attention in what context this information makes sense. He analyzes whether this information can be applied in any situation or only under specific conditions. The last principle infers the studying of options or alternatives, just like all other elements of critical thinking this skill can be formed by certain training [9].

The strategies which are often referred to in course of students' education are brainstorming, problem formulation, narrowing the information and others. All of them to a certain degree are used by teachers of foreign language. The above mentioned principles, when formed, will allow students and graduates to critically comprehend any information received from the mass media, the Internet, routine communication with colleagues and make the right choice. It is important to emphasize that those principles and characteristics 
of critical thinking are directly interrelated. In the integrated form they are the original "stages" relying on which it becomes possible to use this or that principle of critical thinking when teaching students a foreign language. This correlates to the phases mentioned in other researches: evocation, realization, understanding and reflection [11-12].

Nevertheless, critical thinking doesn't exclude creativity. Visa versa, by critical thinking we mean the ability to think, finding strengths and weaknesses, to evaluate the result and the process of thinking but also includes the ability to understand, analyze, evaluate, synthesize, which, in essence, is a creative process. The creative essence of thinking is revealed at all stages from knowledge to evaluation. The background knowledge is not the same for all students so the phase of referring to this knowledge can take completely various forms and verbal form will largely depend on individual style and personality. The application of methods of developing critical thinking in the process of foreign language teaching has a number of advantages but also may present a challenge to the teacher in terms of control and assessment. Undoubtedly, along with critical thinking students develop their independence, creativity, increase motivation, improve ability to understand context. But difficulties may lie in the problematic evaluation of skills and the complication of control over discipline. Along with the development of skills of reading, it is necessary to develop students' ability to express their thoughts in writing. It is the written speech that is accompanied by the greatest difficulties especially in a foreign language.

Some scientists suppose that the current educational trend to standardize curricula and put emphasis on test results makes it hard for teachers to address critical thinking in the classroom. The focus on "preparation for the test" may mislead the educational process from student-centered instruction and put an emphasis on the content instead [8]. It should be emphasized that the formation of critical thinking skills is linked with the formation of speech skills in the learning process of all types of activity, since the subject of any speech activity is thought. Several researchers thus distinguish between "critical reading", "critical writing", "critical listening" and "critical speaking" [9-10].

\section{Discussion}

Thus in the process of teaching a foreign language the development of critical thinking can be considered as one of the factors in the formation of communicative competence.

Since the primary goal of teaching a foreign language is the communicative activity of students the teaching material must be problematic and the educational process should be organized in such a way that students would have a permanent desire to express themselves and defend their opinion. The ability to formulate a problem, find answers to the questions posed, draw additional information, form a position on a particular issue, back it up with arguments and facts, draw conclusions - all these is the goal of problem-based learning based on critical thinking skills.

Thus problem methods are both a goal and a means of learning as the work on a problem also involves interaction in a team as participants need to exchange knowledge, share experience, ideas, information received and, as a result, come to a mutual decision. Such methodology is based on the principles of the personality-oriented approach (education in cooperation, discussions, round tables, projects etc.), which corresponds to the paradigm of modern education.

When applied, this methodology can track the dynamics of students personal development which means changes in willingness to pose questions about what is happening and their actions, enhance readiness to refer and apply their own experience and not the external sources (teacher, reference book, etc.). It sufficiently increases self-control and as a result self-organization, students begins to understand what, how, why he does certain things and consequently gets an opportunity to organize and control his own 
activities. Students obviously develop abilities to understand phenomena and events and not act according to a prescribed standard.

Haynes and Bailey in the research stress the necessity of posing the right questions to stimulate students' critical thinking skills. In other researches the focus on integrating questioning techniques into class discussions to encourage an environment for learners to reveal and practice critical thinking skills [6-7]. Following the "IDEALS" method in class a teacher can help to integrate methods of critical thinking development and it can be adapted to various level and theme of class:

I - Identify the Problem

D - Define the Context

E - Enumerate the Choices

A - Analyze the Options

L - List Reasons Explicitly

$\mathrm{S}$ - Self-Correct

All in all, teaching a foreign language on a university level shouldn't be limited to forming communicative competence, it should also contribute to critical thinking development though the foreign language. Though formation and development of critical thinking skills should be carried out at all stages of teaching a foreign language, at a university level it becomes crucial. This skill becomes a new important component of modern higher professional education, an substantial factor in the professional competence of the graduate.

\section{Conclusion}

The use of methods of critical thinking in the process of teaching a foreign language contributes not only to the intensification of this process, but also to the development of the motivation for attaining and value attitudes of students. Critical thinking methods allow students to develop the habit of creating their own texts, making adjustments and presenting them to the audience. A student with critical thinking is distinguished by the readiness for planning, flexibility, perseverance, readiness to correct his mistakes, and search for compromise solutions.

\section{References}

1. M. Bonnett, Camb. J. Ed., 29:3, 313-324 (1999)

2. N.S. Kasimov, Education for sustainable development: Experience of West Europe, Russia and Central Asia (Moscow, Lomonosov Moscow state university, 2008)

3. Are They Really Ready To Work? Employers' Perspectives on the Basic Knowledge and Applied Skills of New Entrants to the 21st Century U.S. URL: http://www.p21.org/storage/documents/FINAL_REPORT_PDF09-29-06.pdf

4. R.H. Ennis, The Nature of Critical Thinking: An Outline of Critical Thinking Dispositions and Abilities, URL: http:/faculty. education.illinois.edu/rhennis/documents/TheNatureofCriticalThinking_ 51711_000.pdf

5. J. T. Broadbear, J. Schol. Teach. Learn., 3:3, 1-8 (2003).

6. T. Haynes, G. Bailey, Business Education Forum, 57, 33-37 (2003).

7. H. E. Hemming, McGill J. Educ., 35, 173 (2000).

8. L. G. Snyder, M. J. Snyder, J. Res. Bus. Educ., 50, 2 (2008). 
9. R. Nault, Teaching Critical Thinking: Selected Readings Compiled, BBA - WLU, Canada, 1987, CELTA - Canada, 2004, MA Development Studies - RUPP, 2010 (TCTV1 July 31, 2014).

10. P. Brodie, K. Irving, Assessment \& Evaluation in Higher Education, 32:1, 11-19 (2007).

11. S. Hannon, H. McBride, B. Burns, Industry and Higher Education, 18:2, 95-100 (2004).

12. R. Feldman, S. Schwartzberg, Thinking critically: A psychology student's guide (New York., McGraw-Hill, 1990). 
